\title{
Cortical auditory plasticity in children with Cochlear implants
}

\author{
Mozafar Sarafraz ${ }^{1}$, Meysam Kiani ${ }^{1}$, Arash Bayat ${ }^{2}$, Soheila Nikakhlagh ${ }^{1}$, Majid Karimi $^{3}$, Mina Riahii ${ }^{4}$ Nader Saki ${ }^{5}$
}

\begin{abstract}
Objectives: The purpose of the current study was to investigate plasticity of auditory system following cochlear implants (CI) in prelingually severe to profound hearing-impaired children using cortical auditory evoked potentials (CAEPs) and correlate it with auditory perception performance.

Methods: A total of 28 (15 boys, 13 girls) children with profound hearing loss, who underwent $\mathrm{Cl}$ at Ahvaz Jundishapur University of Medical Sciences, Iran, were included in this study. Their mean age at the time of implantation was 21.3 months. All children were evaluated before implantation and 3 months after implantation using the CAEPs and categorical auditory performance (CAP). For CAEP measurement, the stimuli on the HEARLab system $(/ \mathrm{m} /, / \mathrm{g} /$, and $/ \mathrm{t} /)$ were extracted from running speech and presented at $65 \mathrm{~dB} \mathrm{SPL}$.

Results: The mean CAP and $\mathrm{P} 1$ amplitude values were increased from pre- $\mathrm{Cl}$ condition to 3 -month post- $\mathrm{Cl}$ condition (Paired $\mathrm{t}$-test, $p<0.001)$. We found a positive correlation between P1 amplitude and CAP score changes from pre- to post-implantation stages (Pearson's $r=0.62, p=0.018$ ). There was no significant difference in CAP and P1 amplitude values between boys and girls $(p>0.05)$.

Conclusion: The present study indicated that early cochlear implantation, will improve cortical auditory plasticity and auditory performance ability in pre-lingual hearing-impaired children.
\end{abstract}

Keywords: Cochlear implantation, categorical auditory performance, plasticity, children

\section{INTRODUCTION}

Normal development of the auditory cortex is largely dependent on sufficient auditory stimulation. Because of the increased potential of the cortex to be altered during early childhood period, either auditory stimulation or auditory deprivation can seriously influence the maturation of auditory cortical structures and associated behavioral abilities $(1,2)$.

Cochlear implants $(\mathrm{Cls})$ are the most effective neural prosthesis for delivering auditory inputs to individuals with severe to profound hearing loss by bypassing the damaged cochlea and directly stimulating the auditory nerves (3-5). It seems that within 3-6 month post-implantation, auditory cortex undergoes significant reorganization and some alternations in stimulus processing and discrimination can be seen within days after the initial processor fitting (6-9).

The neurocognitive functions related to the perception of acoustic stimuli can be studied by recording cortical auditory evoked potentials (CAEPs). CAEPs are beneficial methods for the objective assessment of central auditory processing, and neural encoding of speech stimuli. These

Potentials are non-invasive and do not depend on subject attention on a specific task, and can be used to evaluate individuals who cannot adequately cooperate (10-12).

The first CAEP component observed, P1, reflects the processing of acoustic stimuli at the thalamo-cortical level and in primary auditory cortex. Recent evidences have shown that the P1 can be utilized for objectively predicting $\mathrm{Cl}$ outcomes as well as improving candidacy and implant programming (13-16). The presence of P1 following activation of

\footnotetext{
Hearing Research Center, Imam Khomeini Hospital, Ahvaz Jundishapur University of Medical Sciences, Ahvaz, Iran

2 Musculoskletal Rehabilitation Research Center, School of Rehabilitation Sciences, Ahvaz Jundishapur University of Medical Sciences, Ahvaz, Iran

3 Department of Audiology, School of Rehabilitation Sciences, Iran University of Medical Sciences, Tehran, Iran

${ }^{4}$ Critical Care Department, University of Manitoba,Winnipeg, Canada

5 Hearing Research Center, Ahvaz Jundishapur University of Medical Sciences, Ahvaz,

Iran
}

\author{
Correspondence: Nader Saki \\ Hearing Research Center, Ahvaz Jundishapur University of Medical Sciences, Ahvaz, \\ Iran \\ E-mail: ahvaz.ent@gmail.com
}

Received: 18 Apr 2018, Accepted: 1 Jul 2018

(C) 2018 by the authors; licensee Modestum Ltd., UK. This article is an open access article distributed under the terms and conditions of the Creative Commons Attribution License (http://creativecommons.org/licenses/by/4.0/). 
Table 1: The capacity of auditory performance (CAP)

\begin{tabular}{cl}
\hline Category & Criteria \\
\hline 0 & No awareness of environmental sounds \\
\hline 1 & Awareness of environmental sounds \\
\hline 2 & Response to speech sounds \\
\hline 3 & Identification of environmental sounds \\
\hline 4 & Discrimination of some speech sounds without lip-reading \\
\hline 5 & Understanding of common phrases without lip-reading \\
\hline 7 & Understanding of conversation without lip-reading \\
\hline
\end{tabular}

the $\mathrm{Cl}$ devices supports the assumption that the deep layers of auditory cortex may develop to some extent even in the absence of auditory stimulation.

The purpose of the current study was to investigate plasticity of auditory system following $\mathrm{Cl}$ in prelingually severe to profound hearing-impaired children using P1 component of CAEPs and correlate it with auditory perception performance.

\section{MATERIALS AND METHODS}

\section{Study Population}

Twenty-eight congenitally profoundly hearing-impaired children (15 boys, 13 girls) who received a cochlear implant before the age of 3 years participated in this study. Their mean age at the time of implantation was 21.3 months (range: 18 months to 2 years 9 months). All participants were born to hearing parents and were identified as having hearing loss within the first six-month of life following the implementation of regional hearing screening program (14). All children in the current study were followed longitudinally as part of a comprehensive, "Cl-Registry" study at Ahvaz Jundishapur University of Medical Sciences (AJUMS), Iran.

All children had a complete insertion of electrode into the cochlea and have attended regular pre- and post-operative rehabilitation sessions.

The protocol and procedures of this investigation were approved by the Ethics Committee of the AJUMS (Registration number: IR.AJUMS.REC.1396.245) which were in complete accordance with the ethical standards and regulations of human studies of the Helsinki declaration (2014). After the enrollment of the subjects, all of the procedures of this study. The procedures, potential benefits and risks of this study were clearly explained to the parents of the children and after that the written consent forms were obtained from all the parents.

\section{Experimental Procedures \\ CAEP test}

The CAEP assessments was carried out in a sound-treated room using the HEARLab system (National Acoustics Laboratory and Frye Electronics). A single channel electrode montage was utilized for all participants. The active and ground electrodes were placed on vertex $(\mathrm{Cz})$ and forehead $(\mathrm{Fz})$ sites, respectively. The reference electrode was also placed on right or left mastoid. The inter-electrode's impedances were kept $<5 \mathrm{k} \Omega$.

The children were evaluated in a comfortable chair, with the speaker adjusted to their head height at one meter away. The stimuli on the HEARLab system $(/ \mathrm{m} /, / \mathrm{g} /$, and $/ \mathrm{t} /$ ) were extracted from running speech and presented at $65 \mathrm{~dB}$ SPL $(0.9 / \mathrm{s}$ presentation rate; alternating polarity). These vowel-free stimuli were selected because they have a spectral content in the mid-, low-, and high-frequency areas, respectively. The stimulus length for the $/ \mathrm{m} / \mathrm{and} / \mathrm{t} /$ vowels was $30 \mathrm{msec}$ and for the /g/, $21 \mathrm{msec}$. The amplitude of $\mathrm{P} 1$ wave was recorded prior to $\mathrm{Cl}$ operation and 3-month post- $\mathrm{Cl}$.

\section{Categories of Auditory Perception (CAP) test}

Auditory perception was assessed with the CAP test, an 8-point hierarchical scale of auditory performance (Table 1). The CAP scale ranges from no awareness of environmental sound (category 0 ) to conversational use of the telephone with a known speaker (category 7) (15).

\section{Statistical analysis}

Statistical analyses were performed using the SPSS software (ver. 17.0). The normality of the data was confirmed by Kolmogorov-Smirnov test and then the comparisons were performed using parametric tests. Pair sample t-test was used 
Table 2: The mean P1 amplitude ( $\pm S D$ ) before and after cochlear implantation

\begin{tabular}{|c|c|c|c|}
\hline \multirow[b]{2}{*}{ Sound Stimulus } & \multicolumn{2}{|c|}{ P1 amplitude $(\mu \mathrm{V})$} & \multirow{2}{*}{$p$-value } \\
\hline & Pre-Cl & 3 months after $\mathrm{Cl}$ & \\
\hline$\backslash \mathrm{m} \backslash$ & $0.51(0.14)$ & $1.09(0.20)$ & $<0.001$ \\
\hline$\backslash t \backslash$ & $0.63(0.29)$ & $1.12(0.54)$ & $<0.001$ \\
\hline $\mid g \backslash$ & $0.65(0.25)$ & $1.21(0.35)$ & $<0.001$ \\
\hline
\end{tabular}

to compare P1 amplitude during pre- and post-implantation phase of study. The significance level was set as 0.05 for all statistical analyses.

\section{RESULTS}

The mean values of P1 amplitude for different speech stimuli at pre-implantation and follow-up period are presented in Table 2. Our findings revealed that the mean $\mathrm{P} 1$ amplitudes has been increased from pre- $\mathrm{Cl}$ condition to pre- $\mathrm{Cl}$ stage for all tested sounds (Paired t-test, $p<0.001$ ).

The mean CAP scores after 3-month implantation $(2.16 \pm 0.47)$ significantly improved compared to pre-Cl $(0.53 \pm 0.51)$ condition (Paired t-test, $p<0.001$ ).

Pearson's correlational analysis indicated a positive correlation between P1 amplitude and CAP score changes from pre- to post-implantation ( $r=0.62, p=0.018)$.

No significant differences in the group averages for $\mathrm{P} 1$ amplitude were found between the different speech stimuli of $/ \mathrm{m} /, / \mathrm{g} /$, and $/ \mathrm{t} /(p>0.05)$. In addition, the present results indicated that the gender had no significant effect with the change in the CAP score $(p=0.091)$ and P1 amplitude $(p=.064)$ after implantation.

\section{DISCUSSION}

Using CAEPs, it is possible to non-invasively determine the maturational status of the auditory cortex in a given subject using various biomarkers. In hearing-impaired children, CAEPs provide a useful tool for assessing whether auditory stimulation via cochlear implantation is appropriate. In addition, these potentials reflect different stages of sensitive periods during which auditory input must be provided. In this article, we recorded the P1 component as a biomarker of primary auditory cortex development in humans. It has been shown that the decrease in P1 latency and increase in P1 amplitude reflect maturational alternations in the auditory cortex, including improved synaptic connections, decreased refractory periods, and improved myelination, much of which initiate as a result of auditory stimulation.

In the present study, we evaluated the development of central auditory maturation (as evidenced by increases in P1 amplitude) in children who received multichannel $\mathrm{Cl}$ in early childhood. We found that P1 amplitude revealed significant improvement following 3 months experience of implantation. Kral et al. (16) have demonstrated that congenitally deaf cats show an atypical pattern of activation within the layers of the primary auditory cortex. They reported that early stimulation with a $\mathrm{Cl}$ leading to a more neural organization within and between cortical layers resulting in robust cortical responses and shorter response latencies across time.

Hearing loss during the first years of life results in sensory deprivation, which in returns prevents normal growth and proper formation of the neural connections essential to form a functional sensory system. Therefore, children with a history of early auditory deprivation reveal structural and functional changes in their auditory system, which in turn influences the results they can obtain using the amplification devices such as cochlear implants.

Sharma et al. recorded CAEPs in congenitally profound hearing-impaired children using multichannel $\mathrm{Cl}$ devices (age range: 1.3 to 17.5 years) who had at least 6 months of experience with their prosthesis. A comparison of cortical responses in the children using Cls with those of age-matched normal-hearing children showed that subjects with devices who had the longest period of auditory deprivation before $\mathrm{Cl}$ operation ( $\geq 7$ years) revealed abnormally late CAEPs, and those who had the shortest period of auditory deprivation ( $\leq 3.5$ years) demonstrated age-appropriate latency responses (17).

\section{CONCLUSION}

The present study evaluated the effects of $\mathrm{Cl}$ on the reorganization of the cortical auditory system in prelingually deaf children using CAEPs. Moreover, the averaged P1 amplitude showed no significant difference between the different speech stimuli in different assessment intervals. Our findings demonstrated that $\mathrm{Cl}$ influences the auditory system and CAEP is a reliable method to measure these effects. 


\section{ACKNOWLEDGEMENTS}

This research was supported by the Research Deputy of AJUMS, Ahvaz, Iran (Grant number: HRC-9602).

\section{REFERENCES}

1. Kral A. Auditory critical periods: a review from system's perspective. Neuroscience 2013;247:117-33. https://doi.org/10.1016/j.neuroscience.2013.05.021 PMid:23707979

2. Kral A, Sharma A. Developmental neuroplasticity after cochlear implantation. Trends Neurosci. 2012;35(2):11122. https://doi.org/10.1016/j.tins.2011.09.004 PMid:22104561 PMCid:PMC3561718

3. Saki N, Yadollahpour A, Moniri S, Karimi M, Bayat A, Abshirini $H$, et al. Investigating the impacts of cochlear implantation on the happiness and self-esteem of mothers of children with severe hearing loss. Int J Mental Health Addict 2017;15:288-94. https://doi.org/10.1007/s11469-016-9672-4

4. Campbell R, MacSweeney $\mathrm{M}$, Woll B. Cochlear implantation $(\mathrm{Cl})$ for prelingual deafness: the relevance of studies of brain organization and the role of first language acquisition in considering outcome success. Front Hum Neurosci. 2014;8:834. https://doi.org/10.3389/fnhum.2014.00834 PMid:25368567 PMCid:PMC4201085

5. Burdo S, Razza S, Di Berardino F, Tognola G. Auditory cortical responses in patients with cochlear implants. Acta Otorhinolaryngol Ital 2006;26:69-77. PMid:16886849 PMCid:PMC2639983

6. Sandmann P, Plotz K, Hauthal N, de Vos M, Schönfeld R, Debener S. Rapid bilateral improvement in auditory cortex activity in postlingually deafened adults following cochlear implantation. Clin Neurophysiol. 2015;126(3): 594-607. https://doi.org/10.1016/j.clinph.2014.06.029 PMid:25065298

7. Petersen B, Gjedde A, Wallentin M, Vuust P. Cortical plasticity after cochlear implantation. Neural Plast 2013; 2013:318521. https://doi.org/10.1155/2013/318521 PMid:24377050 PMCid:PMC3860139

8. Kral A, Tillein J, Heid S, Klinke R, Hartmann R. Cochlear implants: cortical plasticity in congenital deprivation. Prog Brain Res 2006;157:283-313. https://doi.org/10.1016/S0079-6123(06)57018-9

9. Sharma A, Nash AA, Dorman M. Cortical development, plasticity and reorganization in children with cochlear implants. J Commun Disord 2009;42:272-79. https://doi.org/10.1016/j.jcomdis.2009.03.003 PMid:19380150 PMCid:PMC2696307

10. Lee S, Bidelman GM. Objective identification of simulated cochlear implant settings in normal-hearing listeners via auditory cortical evoked potentials. Ear Hear 2017;38(4):e215-e226. https://doi.org/10.1097/AUD.0000000000000403 PMid:28125444

11. Johnson JM. Late auditory event-related potentials in children with cochlear implants: a review. Dev Neuropsychol. 2009;34:701-20. https://doi.org/10.1080/87565640903265152 PMid:20183728

12. Kujala T, Näätänen R. The adaptive brain: a neurophysiological perspective. Prog Neurobiol 2010;91:55-67. https://doi.org/10.1016/j.pneurobio.2010.01.006 PMid:20117165

13. Jang JH, Jang HK, Kim SE, Oh SH, Chang SO, Lee JH. Analysis of P1 latency in normal hearing and profound sensorineural hearing loss. Clin Exp Otorhinolaryngol. 2010;3(4):194-8. https://doi.org/10.3342/ceo.2010.3.4.194 PMid:21217959 PMCid:PMC3010537

14. Saki N, Bayat $A$, Hoeinabadi R, Nikakhlagh $S$, Karimi M, Dashti R. Universal newborn hearing screening in southwestern Iran. Int J Pediatr Otorhinolaryngol 2017;97:89-92. https://doi.org/10.1016/j.ijporl.2017.03.038 PMid:28483258

15. Archbold S, Lutman ME, Marshall DH. Categories of auditory performance. Ann Otol Rhinol Laryngol Suppl. 1995;166:312-14. PMid:7668685

16. Kral A, Hartmann R, Tillein J, Heid S, Klinke R. Hearing after congenital deafness: central auditory plasticity and sensory deprivation. Cereb Cortex. 2002;12:797-807. https://doi.org/10.1093/cercor/12.8.797 PMid:12122028

17. Sharma A, Nash AA, Dorman M. Clinical application of the P1 cortical auditory evoked potential biomarker in children with sensorineural hearing loss and auditory neuropathy spectrum disorder cortical development, plasticity and re-organization in children with cochlear implants. J Commun Disord. 2009;42:272-279. https://doi.org/10.1016/j.jcomdis.2009.03.003 PMid:19380150 PMCid:PMC2696307 